\title{
Governança em rede: o caso do sistema brasileiro de museus
}

Átila Bezerra Tolentino*

\section{Resumo}

A partir da literatura sobre os diferentes conceitos de sistemas e redes sociais e suas implicações na implementação das políticas públicas, sobretudo do conceito de "Estado Rede", proposto por Manuel Castells, o presente artigo analisa a atuação do Sistema Brasileiro de Museus - SBM, criado por meio do Decreto n. 5.264/2004, como uma das metas da Política Nacional de Museus do Brasil.

Palavras-chave: Estado Rede. Redes sociais. Políticas públicas. Sistema Brasileiro de Museus.

\section{Governance by network: the case of Brazilian Museums System}

From the literature on the different concepts of systems and social networks and their implications in the implementation of public policies, especially the concept of "Network State", proposed by Manuel Castells, this article analyzes the performance of the Brazilian Museums System - SBM created by the Decree n. ${ }^{\circ} 5.264 / 2004$, as one of the goals of the National Museums Policy of Brazil.

Keywords: State Network. Social networks. Public policies. Brazilian System of Museums.

\section{Sistemas e redes: interconexões dinâmicas e inovação como essência}

"Governar em rede é difícil, realmente difícil. Há inúmeras maneiras de dar errado". Essa afirmação do cientista político John Donahue (apud GOLDSMITH; EGGERS, 2006: 39) reflete bem os desafios inerentes da forma de atuação do "Estado rede" indicado por Castells (1998). Segundo o sociólogo catalão, o "Estado rede" não é só uma nova utopia da era da informação. Ele é a forma institucional que surge e se adequa aos novos problemas de administração pública e de gestão política (Castells, 1998). 
Ao analisar a sociedade em rede, Castells (1999: 565) expõe que as funções e os processos dominantes da era da informação estão cada vez mais organizados em torno de redes. E complementa:

\begin{abstract}
Redes constituem a nova morfologia social de nossas sociedades e a difusão da lógica de redes modifica de forma substancial a operação e os resultados dos processos produtivos e de experiência, poder e cultura. Embora a forma de organização social em redes tenha existido em outros tempos e espaços, o novo paradigma da tecnologia da informação fornece a base material para sua expansão penetrante em toda a estrutura social (CASTELLS, 1999: 565).
\end{abstract}

Na esteira de "Estado Rede", os museus, a partir dos anos 1980, passaram por uma onda de articulação, envolvendo o Estado e a iniciativa privada, aí incluída a sociedade civil organizada. Na maioria dos casos, com exceção de Portugal, onde foi criada a Rede Portuguesa de Museus - RPM (1999), essa articulação é chamada de sistema: Sistema Brasileiro de Museus (2004), Sistema Espanhol de Museus (1987), Sistema de Museus da Colômbia (1997), Sistema de Museus da Catalunha (1990), Sistema Andaluz de Museus (1984), entre outros.

Essa organização social em redes de que trata Castells, alguns autores chamam de "redes sociais", de modo a diferenciar dos inúmeros conceitos, acepções e aplicações em que o termo "rede" pode ser útil. Para García, entre os distintos usos do conceito de "rede social", o mais comum é o que se refere à "rede como uma forma de intervenção social", uma vez que na maioria dos casos as redes sociais respondem a uma intenção específica de intervenção e melhoria de uma determinada comunidade. Também explica que os "vínculos são os elementos determinantes das redes". A vinculação é, por natureza, bidirecional, e, nos casos das redes sociais, é horizontal e não vertical (GARCÍA, 2007: 2).

A questão da horizontalidade e verticalidade das relações é o principal ponto que evidencia a distinção entre redes e sistemas ressaltada por alguns autores. A horizontalidade vem contrapor as estruturas hierarquizadas, desburocratizando as relações, propiciando a troca direta de ideias entre os membros e, consequentemente, estimulando a criatividade de ações e de respostas mais 
efetivas à resolução de problemas. Maria Olímpia e Henri Campagnolo indicaram, no Fórum Internacional Redes de Museus, promovido pela RPM, em 2001, que:

\begin{abstract}
Embora a noção de sistema não implique necessariamente que o diagrama das suas relações internas seja de natureza hierarquizada (arborescente ou linear), a rede é apreendida, por certos autores, como "encontrando-se em oposição às estratégias de integração vertical e de controle hierárquico dos recursos" ou como "desenvolvendo-se num modo mais flexível" e segundo uma poderosa dinâmica relacional, organizacional e contratual (LAMEIRAS-CAMPAGNOLO; CAMPAGNOLO, 2002: 28).
\end{abstract}

Os expositores também ressaltaram que, enquanto o sistema pode ser definido como um "conjunto de elementos interdependentes expressamente escolhidos com o fim de responder a uma finalidade global", a rede aparece como um "conjunto de elementos (nós e conexões) 'em construção', cuja finalidade, embora mantida globalmente, pode acolher sucessivas alterações pontuais ou eventuais retificações" (Idem: 26-27).

Essa ideia de uma rede ser alimentada pela articulação ou conexões entre distintos nós também é apontada por Castells. Para ele, a "rede é um conjunto de nós interconectados" e, ademais, "são estruturas abertas capazes de expandir de forma ilimitada, integrando novos nós desde que consigam comunicar-se dentro da rede, ou seja, desde que compartilhem os mesmos códigos de comunicação" (CASTELLS, 1999: 566). Essa interconexão, que distingue as redes dos sistemas, está estritamente relacionada à horizontalidade, o que propicia a dinamicidade das ações desenvolvidas nesse modo de relação.

Trazer essas questões para o debate no âmbito das políticas públicas significa reconhecer a importância da participação dos diferentes atores interessados no processo de sua construção e implementação. Bonafont ressalta que as políticas públicas não podem nem devem ser entendidas unicamente a partir do planejamento realizado por especialistas que atuam alheios à sociedade. Pelo contrário, devem ser resultado de uma interação constante entre organizações governamentais e grupos privados, cujo resultado pode adotar formas bem distintas (BONAFONT, 2004: 74). 
Trabalhando esse tema, Cristina Zurbriggen aponta que o conceito de policy networks (redes de políticas públicas), desenvolvido por David Marsh e R. A. Rhodes, surge como uma forma específica de "governança ${ }^{1}$ " e que se trata de um modelo de intermediação de interesses que aparece como consequência dos limites dos modelos tradicionais para analisar as diversas formas de articulação entre Estado e sociedade civil, na condução e implementação das diversas áreas das políticas públicas (Zurbriggen, 2003: 3). Assim, a introdução das redes de políticas públicas é uma forma de admitir que elas emergem da interação entre atores públicos e privados, aceitando que o Estado não é o ator dominante nos processos de elaboração e implementação de políticas públicas e que existe uma variedade de atores não governamentais que participam do cenário público e dos processos de tomada de decisões (Idem: 9-10).

Laura Bonafont (2004) também elabora importante trabalho sobre as redes de políticas públicas. A autora enfatiza que um dos objetivos da análise das redes consiste em identificar e classificar a pluralidade de formas de dirigir e gerir as políticas públicas em nível setorial nas sociedades avançadas; ela apresenta conceitos e tipologias de distintas redes de políticas públicas. O seu estudo possibilita ao gestor público avaliar e analisar as redes de políticas públicas sob diferentes variáveis, que levam em consideração o número de participantes e o tipo de atores envolvidos, os cenários institucionais de interação, os tipos de relação entre os participantes, as relações de poder predominantes, entre outras. As tipologias servem como ponto de partida, a partir do qual se definem hipóteses sobre quem governa, como governa, por que governa e em interesse de quem se governa. De forma semelhante, Goldsmith e Eggers (2006: 22) constituem estudo sobre o novo formato do setor público ao governar em rede, defendendo que o modelo tradicional e hierárquico de governo não atende às demandas dos tempos complexos e em rápida transformação. Essa afirmação embasa a ideia de que a organização em rede desses diferentes atores envolvidos nas políticas públicas propicia o desenvolvimento de dinâmicas culturais e de gestão inovadora. Os autores afirmam também que os governos dependem menos de servidores públicos em papéis tradicionais e mais de uma teia de parcerias, contratos e alianças para realizar o trabalho público. Para eles, esse novo modelo de governo não centraliza as principais responsabilidades dos executivos na gestão de pessoas ou programas, 
mas sim na organização de recursos, muitas vezes pertencentes a outros, de modo a produzir "valor público". Ou seja, o objetivo dos esforços dessa relação em rede é produzir o máximo de "valor público", maior do que seria se cada ator solitário poderia realizar atuando sem colaboração (Idem: 22).

O "valor público" de que tratam esses autores reforça a ideia de "empoderamento" das relações que constituem uma rede social, bem como propicia o "empoderamento", no caso de redes de políticas públicas, dos distintos atores envolvidos no cenário de construção e implementação dessas políticas.

\begin{abstract}
A relação entre redes e poder também é salientada por Castells. O autor expõe que a morfologia da rede é uma fonte de drástica reorganização das relações de poder. As conexões que ligam as redes representam os instrumentos privilegiados do poder. Assim, os conectores são os detentores do poder. Uma vez que as redes são múltiplas, os códigos interoperacionais e as suas conexões tornam-se as fontes fundamentais da formação, orientação e desorientação das sociedades (CASTELLS, 1999: 566-567).
\end{abstract}

Nessa perspectiva, os sistemas ou redes de museus podem configurar-se como uma ferramenta de empoderamento dos distintos atores sociais e como uma inovação no modelo de gestão da administração pública, na medida em que redesenham a relação do governo com o setor museológico, tornando-a participativa e democrática, e conferem um maior "valor público" às ações desenvolvidas pelo Estado. A experiência do Sistema Brasileiro de Museus - SBM, criado por meio do Decreto n. 5.264/2004, pode ser considerado como exemplo de atuação em rede em prol da implementação de uma política pública específica.

\title{
Antecedentes do SBM: o Programa Nacional de Museus e o Sistema Nacional de Museus
}

Em pleno regime militar, o então Instituto Joaquim Nabuco de Pesquisas Sociais (hoje Fundação Joaquim Nabuco) promoveu, no período de 22 a 26 de outubro de 1975, o Encontro Nacional de Dirigentes de Museus, do qual participaram representantes e diretores de museus de todo o País e renomados intelectuais da época, como o sociólogo e antropólogo Gilberto Freyre e Aloísio Magalhães, então diretor do Centro Nacional de Referência Cultural. O objetivo do encontro foi "estudar a situação dos museus em nosso país" e 
estudar e propor soluções lúcidas e viáveis para possíveis problemas existentes, de modo a se estabelecer as bases para a adoção de uma política museológica de capacitação dos museus, com vistas à sua dinamização, para uma atuação permanente a serviço da comunidade e do país (BRASIL, 1976: 6).

Esse encontro resultou na formatação do documento "Subsídios para implantação de uma política museológica brasileira", publicado no ano seguinte. Esses subsídios compunham-se de sugestões e recomendações para a implantação de uma possível política museológica brasileira. O documento apresenta recomendações nas áreas de organização técnica e administrativa, capacitação financeira, capacitação profissional, pesquisa, educação, preservação do patrimônio cultural e relação com o meio.

Seis anos após a edição desse documento, foi criado, em 1982, no âmbito da antiga Fundação Pró-Memória, o Programa Nacional de Museus ${ }^{2}$. Esse programa lançou os fundamentos de uma nova proposta museológica para o país, priorizando os aspectos relativos à segurança, modo de exposição e preservação dos acervos. Segundo Maria Célia Santos, esse programa pretendia dar assistência aos museus do país, mas, em primeira instância, cuidaria da administração, de uma forma integrada, dos museus que atuavam na órbita da Secretaria de Cultura do então Ministério de Educação e Cultura (SANTOS, 1994).

Após a criação do Ministério da Cultura - MinC, foi instituído, por meio da Portaria/MinC n. ${ }^{\circ}$ 313, de 16 de agosto de 1986, o antigo Sistema Nacional de Museus - SNM. O SNM tinha como objetivo estabelecer uma política nacional para o setor e possuía programa de cursos, oficinas, publicações, orientação na formulação de projetos e revitalização dos museus. As discussões das ações do SNM se davam no âmbito do Comitê Nacional, formado por membros representativos da área museológica dos estados, da Fundação Casa de Rui Barbosa, da Fundação Nacional de Artes, do Conselho Federal de Museologia e do Iphan (representado pela Coordenadoria de Acervos Museológicos), que se reunia anualmente. O Programa Nacional de Museus tornou-se o braço executor e de apoio logístico dos projetos aprovados pelo SNM, no âmbito de seu Comitê 
Nacional. O Comitê Nacional também discutia as prioridades para o setor, a implantação de programas de apoio aos museus e as ações de capacitação. Um dos méritos do comitê é que sua atuação neutralizava, de uma certa forma, a interferência política na aprovação dos projetos apresentados ao SNM.

Entretanto, com a falta de uma política pública consistente voltada para o setor museológico, a escassez de recursos e o assolamento no setor cultural provocado pelo Governo Collor no início dos anos de 1990, o SNM não obteve força suficiente para implantar uma política nacional para os museus e dar continuidade a suas ações. Maria Célia Santos critica a atuação do SNM e do Programa Nacional de Museus, ressaltando que pouco contribuíram para uma efetiva transformação no âmbito dos museus. A autora também afirma que as metas usadas por essas instituições estavam atreladas aos objetivos dos órgãos a que estavam vinculados, "frutos de uma política inadequada na área da cultura" (SANTOS, 1994: 63-64). Ela explica que

\begin{abstract}
A organização do Sistema Nacional de Museus foi, em todos os períodos, uma reivindicação da classe. Entretanto, a sua implantação não contribuiu para sanar os pontos críticos de forma mais satisfatória. O SNM não assegurou a distribuição de recursos nem a circulação de informação, de forma democrática e igualitária, entre as diversas regiões do país, embora tenha havido avanços na oferta de cursos de capacitação, na produção de material bibliográfico, na realização de eventos e na melhoria da infraestrutura de alguns museus (SANTOS, 2008: 219).
\end{abstract}

Embora o comentário da autora tenha fundamento, não se pode esquecer que 0 SNM impulsionou a criação de alguns sistemas estaduais de museus. Isso se deu pelo fato de que a intenção do Comitê Nacional era que todos os estados fossem representados por seus sistemas, apesar de que muitos representantes eram indicados pelas Secretarias de Cultura dos estados. Dos sistemas criados por incentivo do SNM, somente o Sistema Estadual de Museus do Rio Grande do Sul - SEM/RS permanece atuante. Inclusive, o SEM/RSembasou a criação do atual Sistema Brasileiro de Museus - SBM. Ou seja, é um processo cíclico: o SNM influenciou a criação de sistemas estaduais de museus, que embasaram a criação do SBM, que, por sua vez, impulsionou a criação de outros sistemas estaduais e municipais de museus ${ }^{3}$. 
Devem ser considerados, entretanto, os distintos contextos em que foram criados o SNM e o SBM. O Programa Nacional de Museus surgiu ainda durante o regime militar e SNM no início da retomada da democracia, atravessando a era Collor, o que contribuiu para que as instituições perdessem força e fossem extintas. Ademais, a sua criação não foi fruto de um intenso processo de discussão com a sociedade civil ligada ao setor museológico, diferentemente da metodologia de implementação da Política Nacional de Museus - PNM, que originou o SBM.

\section{Gestão democrática de uma política: a Política Nacional de Museus e o Sistema Brasileiro de Museus}

Após amplo debate com a comunidade museológica brasileira, o Ministério da Cultura do Brasil lançou, em maio de 2003, a Política Nacional de Museus - PNM, que tem como objetivo:

\footnotetext{
Promover a valorização, a preservação e a fruição do patrimônio cultural brasileiro, considerado como um dos dispositivos de inclusão social e cidadania, por meio do desenvolvimento e o aprimoramento das instituições museológicas existentes e o fomento à criação de novos processos de produção e institucionalização de memórias constitutivas da diversidade social, étnica e cultural do país. (BRASIL, 2003: 8).
}

$\mathrm{Na}$ verdade, a ideia de uma política nacional voltada para o campo museológico já estava prevista no documento de campanha de governo do presidente Luis Inácio Lula da Silva para a cultura, intitulado A imaginação a serviço do Brasil. Nesse documento, é apresentada como proposta o estabelecimento de políticas na área de patrimônio cultural e museus que visem à democratização do acesso aos bens culturais nacionais e estaduais, buscando consolidar políticas públicas voltadas ao resgate da memória e das identidades locais. É também salientada a necessidade de valorizar o patrimônio cultural sob a guarda dos museus, compreendendo que eles têm valor estratégico na afirmação das identidades regionais (PT, 2002). Desta forma, uma das primeiras ações do MinC na gestão do ministro Gilberto Passos Gil Moreira foi propor linhas programáticas para uma política nacional voltada para o setor museológico brasileiro. Assim, no início de 2003, o MinC, por meio da então 
Secretaria do Patrimônio, Museus e Artes Plásticas - SPMAP, convocou a comunidade museológica brasileira para discutir as bases para a PNM.

O relatório de gestão dos dois primeiros anos da Política Nacional de Museus descreve que o processo de construção dessa política, em termos metodológicos, foi dividido em quatro etapas: I - elaboração do documento básico para discussão, com a participação de representantes de entidades e organizações museológicas e universidades, além de profissionais de destacada atuação na área; II apresentação e debate público do documento básico em reuniões ampliadas no Rio de Janeiro e em Brasília, com a participação de diretores de museus, representantes de secretarias de cultura, professores de universidades e representantes de entidades e organizações museológicas de âmbito nacional e internacional; III ampla disseminação e discussão do documento básico por meio eletrônico e em reuniões presenciais, possibilitando que outros interessados no debate pudessem participar e contribuir livre e democraticamente para o aprimoramento da proposta inicial; IV - e finalmente, uma equipe mista, formada por pessoas de dentro e fora do MinC, cuidou de consolidar as diferentes sugestões e de apresentar uma nova versão para o documento inicial. Essa nova versão foi mais uma vez submetida ao debate por meio eletrônico, corrigida, ajustada,, depois publicada e lançada em maio de 2003 (MINISTÉRIO DA CULTURA, 2005: 11-12).

Uma das premissas dessa Política é a

\footnotetext{
constituição de uma ampla e diversificada rede de parceiros que, somando esforços, contribuam para a valorização, a preservação e o gerenciamento do patrimônio cultural brasileiro, de modo a torná-lo cada vez mais representativo da diversidade étnica e cultural do país (Brasil, 2003: 9).
}

Vale ressaltar que a PNM representou uma mudança de postura do MinC, tendo em vista que abrange todos os museus brasileiros, independentemente da sua vinculação institucional, ou se público ou privado. Em todo o texto está premente a articulação entre os entes da federação e a sociedade civil, bem como há a preocupação com a consolidação de políticas públicas não só voltadas aos bens culturais nacionais, mas também aos estaduais e municipais. 
Inúmeras são as dificuldades na implementação de uma política pública em nível nacional e que seja transversal a todos os entes da federação e que propicie, ainda, a participação da sociedade civil. Nas palavras de Graça Rua, em especial quando uma política envolve diferentes níveis de governo - federal, estadual e municipal ou diferentes regiões de um mesmo país, ou ainda, diferentes setores de atividade, a implementação pode ser problemática, já que o processo se torna mais complexo e mais difícil de ser controlado (RUA, 1998). No entanto, uma política advinda do governo federal, que pretende ser nacional, não se pode restringir a sua estrutura.

A participação de setores não governamentais e de instituições das diferentes instâncias governamentais na implementação da PNM corrobora o que Silva e Melo afirmam em sua análise sobre o processo de implementação de políticas públicas no Brasil, sobretudo no que tange ao trabalho de articulação em rede:

\footnotetext{
O conceito de redes de implementação é particularmente apropriado para capturar o fato de que as políticas públicas são implementadas fundamentalmente através de redes de agentes públicos e, cada vez mais frequentemente, também por agentes não governamentais. [...] Ao se reconhecer o jogo político como essencial à vida democrática e fundamental para o controle social da ação do governo, contribuições recentes têm enfatizado a importância de se incorporar stakeholders - grupos envolvidos pelas políticas e nela interessados - ao processo de formulação e implementação de políticas (SILVA e MELO, 2000: 12).
}

Em sua implementação, o primeiro reflexo da PNM foi a mudança do escopo do Programa Museu, Memória e Cidadania, integrante do Plano Plurianual - PPA do Governo Federal. Anteriormente voltado apenas para os museus federais - e na prática somente aos museus vinculados ao próprio MinC -, o Programa foi reformulado para o período de 2004-2007 e passou a abranger todos os museus brasileiros, de modo a ter consonância com a PNM. Além disso, as ações do programa também foram reformuladas, a fim de ter coerência com os eixos programáticos da PNM.

Tais ações deram a força necessária para a criação do Departamento de Museus e Centros Culturais - Demu)na estrutura do Instituto do Patrimônio Histórico e Artístico Nacional - Iphan, por meio do Decreto n, 5.040/2004. O Demu nasceu da 
reformulação da estrutura do MinC, quando foi extinta a SPMAP. A criação desse Departamento, ao mesmo tempo em que se permitiu a existência de um setor específico para a condução da PNM, foi importante para que a área museológica dispusesse de um canal de interlocução dentro do MinC e para o fortalecimento de uma rede do setor museológico em todo o país ${ }^{4}$.

Além do Departamento de Museus e Centros Culturais, a necessidade de criação do SBM foi apontada no documento original da PNM. Era demanda das instituições museológicas a criação de uma instituição oficial que organizasse os museus do país, sejam eles públicos ou privados, e propusesse as normativas legais referentes à atuação do setor museológico. Ademais, entendia-se que o SBM, instituído pelo Decreto n. 5264/2004, era peça fundamental para o desenvolvimento do campo da gestão e configuração do setor museológico brasileiro, para o fomento das ações dos museus e condução de políticas públicas em nível nacional para o setor. A regulamentação da atuação do SBM por meio de um decreto foi fundamental para institucionalizar a relação dos diferentes atores, que participam do processo de debate da condução da PNM por meio do Comitê Gestor do SBM, e facilita o planejamento das ações a médio prazo. Como observa Bonafat (2004: 71), a capacidade do Estado para cumprir seus objetivos políticos depende do desenvolvimento de um marco normativo. Por meio da regulamentação, elimina-se a dispersão normativa, definem-se as regras do jogo para os distintos atores, reduzindo a margem de negociação de aspectos básicos das políticas em cada subsistema.

A exemplo da formulação da PNM, a concepção do SBM também se deu de uma forma democrática. A minuta do decreto de criação do SBM, antes de ser encaminhada para apreciação da Casa Civil, foi colocada à disposição, em meio eletrônico, para que os profissionais do setor e demais interessados pudessem opinar sobre sua forma de constituição, obtendo-se bastante retorno com contribuições, críticas e sugestões, numa demonstração clara da existência de uma rede da comunidade museológica brasileira que já se vinha constituindo desde a implantação da PNM. 
Cabe destacar que o SBM foi criado em meio a um período de grande efervescência no setor museológico brasileiro, em que a sociedade civil nunca esteve tão próxima do Estado na condução das políticas públicas para a área.

O caráter democrático e participativo desse processo de construção se refletiu na composição do Comitê Gestor do SBM, onde está garantida a representação dos seguintes órgãos ou entidades: MinC, Iphan, Ministério da Educação, Ministério da Defesa, Ministério da Ciência e Tecnologia, Ministério do Turismo, sistemas estaduais de museus, sistemas municipais de museus, museus privados, Conselho Federal de Museologia, ecomuseus e museus comunitários, Comitê Brasileiro do Conselho Internacional de Museus, Associação Brasileira de Museologia e instituições universitárias que tenham cursos relacionados à área de Museologia. Como se observa, o Comitê Gestor não é composto somente de instituições públicas. Com o SBM, a sociedade civil organizada ligada à área museológica adquiriu a oficialização necessária junto ao Estado para poder participar da condução das políticas públicas para o meio museológico, configurando um exemplo claro de inclusão política e social do cidadão no processo decisório 5 .

De fato, a criação da PNM e atuação do SBM trouxeram um novo cenário para o setor museológico no Brasil, sobretudo na abertura de linhas de fomento à qualificação dos museus com diversos editais de apoio financeiro a projetos, democratização do acesso a esses equipamentos culturais, formação e capacitação de profissionais do setor, oferta de cursos de graduação em museologia em todas as regiões do país, criação de um aparato legal de regulamentação da área e democratização do processo de debate e implementação de políticas públicas para o campo museológico.

Exemplo prático de atuação do SBM por meio do seu Comitê Gestor foi a propositura de instrumentos legais para a regulamentação do setor museológico no país, tendo em vista esta ser uma lacuna apontada nos fóruns de discussão para a implementação da PNM. Como observa Tolentino (2007), no ano de 2006, o Comitê Gestor do SBM elaborou o anteprojeto de lei do Estatuto dos Museus e o entregou à Câmara Federal. A Comissão de Educação e Cultura apresentou o anteprojeto ao Plenário da Casa, transformando-o no Projeto de Lei n. 7.568/2006. 
O autor ainda aponta que antes de se chegar ao Congresso Nacional, a primeira formatação da proposta para o Estatuto foi seguida de profícuas discussões no campo museológico brasileiro, envolvendo pessoas e entidades vinculadas à museologia, meio universitário, profissionais da área e secretarias estaduais e municipais de cultura, ambientadas em diversos fóruns e por meio virtual. Coube ao Comitê Gestor do SBM sistematizar as sugestões e contribuições recebidas, consolidando a proposta do Estatuto dos Museus (TOLENTINO, 2007: 82).

Após anos sem uma regulamentação de grande peso na área do patrimônio, desde a edição do Decreto-lei n, 25/37, o Estatuto dos Museus é aprovado no Congresso Nacional por meio da Lei n. 11.904, de 14 de janeiro de 2009, representando, para o setor museológico brasileiro, um grande momento de consolidação para a área, que agora tem em mãos um instrumento legal que respalda suas ações e visa contribuir para uma melhor gestão da atuação dos museus e dos trabalhos por eles desenvolvidos.

Nessa perspectiva, levando em consideração os resultados obtidos após a implementação da PNM, o modo de atuação do SBM pode ser tomado como um exemplo de inovação no modelo de gestão da administração pública, tendo em vista que redesenha a relação do governo com a sociedade, tornando-a participativa e democrática na gestão do patrimônio cultural sob a guarda dos museus e das políticas públicas voltadas para o setor, atuando, desta forma, na esteira do "Estado rede" definido por Castells. Ao estimular o envolvimento dos diversos atores sociais, a experiência do processo de implementação da PNM e a forma de atuação do SBM permitem aferir algumas considerações relevantes acerca das suas estratégias de articulação, as quais contribuem para nova postura na governança das políticas empreendidas pelo governo brasileiro voltadas para o campo museológico:

a) $O$ envolvimento da sociedade civil e de outros atores sociais no processo de criação e implementação da PNM e na gestão do SBM contribui para que o Estado cumpra com sua responsabilização, ao disponibilizar programas, projetos e ações com vistas ao fomento e desenvolvimento do setor museológico brasileiro. Ao mesmo tempo, a sociedade civil, na medida 
em que se reconhece como um importante ator nesse jogo político, pode propiciar um maior controle social sobre a atuação do Estado. Isso se deve ao fato do "valor público" gerado quando as ações são desenvolvidas por meio de uma rede de atores e do empoderamento das relações que constituem uma rede social.

b) O SBM, ao construir uma relação participativa e democrática entre governo e sociedade civil, propicia que o Sistema se consolide, podendo manter suas ações mesmo em ambientes de instabilidade política e em caso de mudanças de governo. A participação da sociedade civil, ao se revestir em um importante ator no jogo político, também pode contribuir para a continuidade das ações do Sistema ao longo de distintos governos.

c) Do item acima, decorre que as políticas públicas construídas e implementadas de forma participativa, com a identificação e o envolvimento dos atores sociais interessados, transformam-se em políticas de Estado e não em políticas de governo.

d) Por fim, os resultados com vistas ao desenvolvimento do campo museológico ocorridos no Brasil após a criação da PNM e do SBM somente foram possíveis tendo em vista que são frutos de uma gestão compartilhada das políticas empreendidas, configurando-se em estratégia eficiente para que o Estado cumpra com as suas responsabilidades e execute suas ações de forma eficaz e efetiva, aumentando o seu "valor público".

Estimular o envolvimento dos diversos atores interessados, aí incluída a sociedade civil, no processo de implementação das políticas públicas de cultura realmente não é uma tarefa fácil, mas é um exemplo de reconhecimento da importância do patrimônio cultural, tanto do ponto de vista econômico como social.

As dificuldades de governar em rede existem, como apontado por Goldsmith e Eggers, sobretudo pelo fato de que 
os sistemas organizacionais, administrativos e de pessoal do governo foram estruturados para operar dentro de um modelo de governo hierárquico e não em rede, e as duas abordagens muitas vezes colidem (2006: 39).

Mas, como também ressaltam os autores (2006: 227), as mudanças significativas em nossa sociedade exigem um governo que atue em rede, tendo em vista que os problemas enfrentados hoje pelos cidadãos são muito complexos e de difícil resolução por uma burocracia hierárquica, centrada somente no Estado, sem o envolvimento dos demais atores sociais importantes no processo de implementação das políticas públicas.

A gestão compartilhada do patrimônio cultural e das políticas voltadas para a sua preservação e promoção é uma estratégia fundamental para que ela seja efetiva e para que o Estado possa cumprir com as suas responsabilidades, conforme se pode inferir das palavras de Castells ao defender que o "Estado rede" surge como a alternativa adequada para os novos problemas de administração pública e gestão política (1998).

Além disso, pode-se acrescentar que a gestão compartilhada das políticas voltadas para os museus é uma perspectiva para a continuidade e perenidade da atuação do Estado (entendido como "Estado rede") em relação às ações decorrentes da PNM, sobretudo pelo envolvimento da sociedade civil. Isso se dá porque o SBM cria o canal de interlocução necessário entre o setor museológico e o governo, propiciando um controle social das ações desenvolvidas pelo Estado, o qual, por sua vez, tem o dever de cumprir com suas responsabilizações perante a sociedade na condução das políticas públicas por ele empreendidas.

$\mathrm{Na}$ área dos museus, os resultados têm sido evidentes. $\mathrm{E}$ a consolidação das políticas públicas para o setor, configuradas como uma política de Estado, tem, como seu principal expoente, a criação do Instituto Brasileiro de Museus. Este, por sua vez, tem, agora, o grande desafio de dar continuidade e ampliação à ação do "Estado rede" para a área dos museus, sem perder o caráter democrático com que têm sido conduzidas as ações decorrentes da PNM. 


\section{Notas}

(1) A literatura apresenta distintas concepções de governança, distinguindo-a, sobretudo, da governabilidade, mas que tendem a variar de autor para autor. Grosso modo, governança é a capacidade que um determinado governo tem para formular e implementar suas políticas (Cead/UnB, 2007: 2). Ou seja, a governança é a capacidade de direcionamento e coordenação, pelo governo, dos atores políticos de uma rede de políticas públicas. Governabilidade, por sua vez, refere-se às condições substantivas e matérias de exercício de poder e de legitimidade do Estado e de seu governo, derivadas da sua postura diante da sociedade civil e do mercado (Cead/UnB, 2007: 2).

(2) Grande parte da atuação do Programa Nacional de Museus e do Sistema Nacional de Museus, descrita neste artigo, teve como base o teor das entrevistas gentilmente concedidas pelas museólogas Sonia Guarita e Célia Corsino, que participaram dos processos de criação dessas instituições na década de 1980.

(3) Após a criação do SBM, foram instituídos o Sistema Estadual de Museus do Ceará, por meio da Lei $\mathrm{n}^{\circ}$ 13.602, de 28 de junho de 2005, regulamentado pelo Decreto $n^{\circ} 28.419$, de 4 de outubro de 2006; o Sistema Estadual de Museus de Santa Catarina, por meio do Decreto $n^{\circ} 4.163$, de 29 de março de 2006; o Sistema de Museus de Pelotas, por meio do Decreto $n^{\circ} 4.895$, de 15 de setembro de 2006; o Sistema de Museus de Ouro Preto, por meio da Lei $n^{\circ} 305$, de 7 de dezembro de 2006; o Sistema de Museus de Mato Grosso, por meio do Decreto $n^{\circ}$ 959, de 5 de dezembro de 2007; o Sistema Municipal de Museus de Rio Grande, pelo Decreto $n^{\circ}$ 9.936, de 26 de maio de 2008; o Sistema de Museus de São Luís, por meio do Decreto $n^{\circ} 35.140$, de 25 de junho de 2008; e o Sistema Alagoano de Museus, pelo Decreto 4.092, de 29 de dezembro de 2008.

(4) Esse mesmo departamento, no ano de 2009, vem a ser transformado no Instituto Brasileiro de Museus Ibram, desvinculando-se do Iphan, por meio da Lei n. 11.906/2009, garantindo a autonomia necessária para a condução da Política Nacional de Museus, eis que se trata de uma autarquia federal específica, também vinculada ao MinC, para cuidar exclusivamente do campo dos museus, sem concorrer com as outras atividades do campo do patrimônio a cargo do Iphan.

(5) Parte do texto do Decreto n. 5264/2004, que cria o SBM, foi recepcionado pela Lei n. 11.904/2009 (Estatuto dos Museus), mais especificamente nos artigos 55 a 63.

\section{Referências bibliográficas}

BONAFONT, Laura C. Redes de Políticas Públicas. Madrid: Centro de Investigaciones Sociológicas, 2004.

BRASIL. Ministério da Educação e Cultura. Departamento de Assuntos Culturais. Instituto Joaquim Nabuco de Pesquisas Sociais. Subsídios para implantação de uma política museológica brasileira. Recife: MEC/DAC/IJNPS. 1976.

BRASIL. Bases para a Política Nacional de Museus: Memória e Cidadania. Ministério da Cultura, Brasília. 2003, Disponivel em: http://www.museus.gov.br/sbm/downloads/Pol\%C3\%ADtica_Nacional_de_\%20Museus.pdf>.. Acesso em: 15 abr. 2013. 
BRASIL. Ministério da Cultura. Política Nacional de Museus: relatório de gestão 2003-2004. Brasília: MinC/Iphan/Demu. 2005.

CASTELLS, Manuel. A era da informação: economia, sociedade e cultura. A sociedade em rede. São Paulo: Paz e Terra. 1999.

Hacia el estado red? Globalización económica e instituiciones políticas en era de la información. (1998).Disponível

em

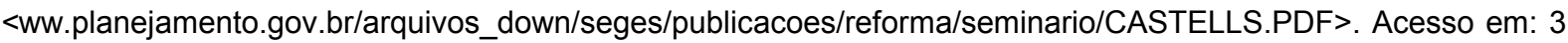
dez. 2007.

CENTRO DE EDUCAÇÃO A DISTÂNCIA/UNB. Especialização em Gestão de Políticas Públicas de Cultura. Módulo 4: Gestão Pública. Brasília: Universidade de Brasília. 2007.

GARCÍA, Marta Rizo. Redes. Una aproximación al concepto. 2007 Disponível em <http://www.oei.es/cultura/cooperacion_cultural.htm>. Acesso em: 21 jun. 2007.

GOLDSMITH, Stephen; EGGERS, Wiliam D. Governar em rede: o novo formato do setor público. Brasília: ENAP/Unesp. 2006.

LAMEIRAS-CAMPAGNOLO; Maria Olímpia; CAMPAGNOLO, Henri. O conceito de rede: incidências sobre o enquadramento e a coordenação das unidades museológicas portuguesas. Actas do Fórum Internacional Redes de Museus. Lisboa. 2002. p. 25-39.

PARTIDO DOS TRABALHADORES. A imaginação a serviços do Brasil. São Paulo, PT, 2002. Disponível em <http://www.pt.org.br/site/assets/cadernocultura.pdf>. Acesso em: mar. 2007.

RUA, Maria das Graças. Análise de políticas públicas: conceitos básicos. Brasília: Paralelo 15. 1998. Disponível em <http://estadoedemocracia.blogspot.com/2007/08/analise-d-politicas-publicas-conceitos.html>. Acesso em: 10 dez. 2007.

SANTOS, Maria Célia T. M. A escola e o museu: uma história de confirmação dos interesses da classe dominante. Cadernos de Museologia. N, 3. Lisboa: ULHT, p. 45-74, 1994.

Encontros museológicos - reflexões sobre a museologia, a educação e o museu Rio de Janeiro: MinC/Iphan/Demu. 2008. (Coleção Museu, Memória e Cidadania, vol. 4).

SILVA, Pedro Luiz Barros; MELO, Marcus André Barreto de. O processo de implementação de políticas públicas no Brasil: características e determinantes de programa e projetos. Caderno n. 48. Campinas: Unicamp/Nepp, 2000.

TOLENTINO, Átila B. Governança em rede: o caso do Sistema Brasileiro de Museus. In RENNÓ, Lucio (Org.). Coletânea de políticas públicas de cultura: práticas e reflexões. Brasília: Universidade Católica de Brasília/Ministério da Cultura. 2011. p. 179-225. 
Políticas públicas para museus: o suporte legal no ordenamento jurídico brasileiro. Revista CPC, São Paulo, n. 4 , p. 72-86, maio/out. 2007.2 Disponível em: $<$ http://www.usp.br/cpc/v1/imagem/conteudo_revista_arti_arquivo_pdf/07_atilatolentino_final2.pdf>.. Acesso em: 15 abr. 2013.

ZURBRIGGEN, Cristina. Las redes de políticas públicas. Una revisión teórica. Boletín IGG n. 149. Institut Internacional de Governabilitat, Catalunha. 2003.

\section{Créditos}

*Especialista em Gestão de Políticas Públicas de Cultura pela Universidade de Brasília. É da carreira de Especialista em Políticas Públicas e Gestão Governamental, do Ministério de Planejamento, Orçamento e Gestão, com atuação no Instituto do Patrimônio Histórico e Artístico Nacional. Coordena a Casa do Patrimônio de João Pessoa, vinculada à Superintendência do Iphan na Paraíba. Tem experiência nas áreas de museologia, políticas públicas para o patrimônio cultural e educação patrimonial. Contato: atilabt@gmail.com. 